\title{
Valedictory editorial from the Chairman of the IFMBE Journal Committee on the occasion of a change of Editors
}

\author{
David Holder
}

Received: 15 November 2012/Accepted: 16 November 2012/Published online: 25 November 2012

(C) International Federation for Medical and Biological Engineering 2012

The management structure of Medical and Biological Engineering and Computing differs slightly from many other similar journals in that it is the official journal of the IFMBE and is a valuable source of income for it. Rather than the usual structure of the editor and their staff, an editorial board and publisher, the IFMBE has created a Federation Journal Committee which oversees management aspects of the journal although not direct editorial matters. These latter are the province of the editor and their editorial board and advisers. This steers a course between the IFMBE and the natural requirement to generate income and the ambition to raise the profile and circulation of the journal. After sitting as member of the FJC, I became Chairman in 2009 and so had the privilege of advising the current editor on management issues with respect to the journal and also lead the search committee for the new editor.

It has been a pleasure and a privilege to work with Jos Spaan over these 7 years while he has been editor. The journal is widely respected in the Medical Physics and Biomedical Engineering fields for its high standards. Jos has made a major contribution to advancing this good reputation. He has willingly and enthusiastically given huge amounts of his time to the editorial process. The lifeblood of the journal is the response time to submitted articles but also the quality of the editorial judgment, both in respect to direct appraisal of submissions and in appointing high quality editorial assistants. Jos has been outstanding in all these respects and I know from personal experience that he has given up many evenings and weekends personally to ensure that the editorial process has been rapid and of the highest standards. The

D. Holder $(\bowtie)$

Department of Medical Physics, University College London, London, UK

e-mail: d.holder@nhs.net quality and scope of submissions in the journal reflect these qualities. We have been very fortunate to have had such a diligent and discriminating editor over this period and this is reflected in the improved impact factor and continuing high standing of the journal. I would also like to thank the team of hard-working and diligent associated editors he recruited who have so willingly given up a great deal of their time to maintaining the high standards of the journal. In particular, I would like to thank Ruben Coronel who has been Deputy Editor and in addition has taken responsibility for new submissions since September 1st of this year in order to free time for the Editor in Chief to prepare for the transition to the new editor.

This will be a hard act to follow. The search for a new editor was protracted as the search committee, with valuable contributions from the immediate and current IFMBE presidents, set out to recruit a new editor with a high existing scientific standing who would be able to continue this tradition of excellence and also increase the high standing of the journal through their reputation and international contacts. Jos's own special interest was in cardiovascular engineering; we have been very fortunate to appoint a new editor with a strong international reputation in the allied field of Neuroengineering, Nitish Thakor. He has a literal international standing in that he has academic appointments in both the USA and Singapore, as well as a wealth of editorial experience and international contacts. $\mathrm{He}$ is an ideal person to further the reputation and standing of the journal and I welcome him to the new position. He has already started the handover and will formally become the new editor from January 2013.

The prospects for the journal are therefore excellent. Of course, there are challenges in the scientific publishing world. These include the increase in submissions, especially from countries who are increasing their scientific 
activity and in whom the pressure to publish has been increasing. At the same time, there are pressures from grant giving bodies such as the National Institutes of Health in the USA for open access publishing, and the model for income generation has shifted markedly in the time I have served on the FJC, from institutional subscriptions to electronic group consortia. These changes will need us to be flexible and move with the times. However, we are fortunate in having a flexible, supportive and forwardlooking publisher, Springer, and I look forward to assisting in the development of new methods to maintain the quality and reputation of the journal as well as its income for the IFMBE. We are entering into a new phase with our new editor in a time when the internet is bringing changes to scientific communication. We have a strong new editor as well as supporting team of editorial assistants and IFMBE officers, and I am confident that the journal will maintain and improve its reputation as a leading means for scientific dissemination in our field. 